\title{
Science Inquiry-Based Activities in Elementary Education: How to Support Teachers' Practices?
}

\author{
Diana Boaventura and Cláudia Faria
}

\begin{abstract}
This investigation was done to understand how to support teachers to adopt innovative inquiry based science practices at elementary education. Here we present the results of two inquiry-based activities that were done in three elementary schools, involving six teachers and a total of $\mathbf{1 4 0}$ students. To understand the process of implementation of each activity by the teachers and its impacts on students, a qualitative methodology was used. The teachers were actively involved in the activities, however, the process followed by them was considerably different in what concerns time allocation. Additionally, instead of joining experiments from the different areas of conceptual knowledge, some of them chose only one separate subject. As a consequence, the students' achievements were also different in each class. In the classes where the students had more time for discussion, more adequate answers were given to the initial questions, whereas, in the classes that devoted less time to the activity some competences, like observation skills and planning experiments were not achieved. It is suggested that although the creation of new curriculum materials can facilitate the adoption of new practices by teachers, this is not sufficient. Teacher's ownership of the activities is perhaps the keystone of this entire process.
\end{abstract}

Index Terms-Inquiry, science education, teaching innovation.

\section{INTRODUCTION}

This investigation was done within a project, "Between tide marks: Integrating literacy's (iLit)" (PTDC/ CPE-CED/ $117923 / 2010$ ), to promote the integration of different kinds of literacy (science, digital, information) through the development of multidisciplinary inquiry-based activities, focused on "real-life" situations.

There is a worldwide consensus that society needs scientifically literate citizens [1], [2]. We live in a complex society where citizens need key competences for personal fulfillment and active citizenship such as communication and digital skills; basic competences on mathematics, science and technology; social and civic competences; a sense of initiative and entrepreneurship; metacognition, cultural awareness and expression [3]. For the 21st century, it was identified the need of the following competences [4]:

- Critical thinking and problem solving: the ability to make decisions, solve problems and take action as appropriate;

Manuscript received February 4, 2014; revised April 3, 2014. This work was supported by the Portuguese Foundation for Science and Technology (FCT) under project PTDC/CPE-CED/117923/2010.

Diana Boaventura is with Escola Superior de Educação João de Deus, Lisboa, Portugal and with Guia Marine Laboratory, Oceanographic Center, Science Faculty of Lisbon University, Portugal (e-mail: d.boaventura@netcabo.pt)

Cláudia Faria is with Institute of Education, University of Lisbon, Portugal (e-mail: cbfaria@ie.ul.pt).
- Effective communication: the ability to synthesize and transmit ideas in both written and oral formats;

- Collaboration: the ability to work effectively with others, including those with opposing points of view;

- Creativity and innovation: the ability to see what's not there and to make something happen.

How can science education contribute to achieve this goal?

The school role is to provide students with learning situations that promote the development of different ways of thinking and working, in which they could practice different work tools and learn to live in the modern world [5]. Considering science education, and looking at the curricula of different countries and taking into account the European recommendations, we now know that science education is crucial for the understanding of the world and for social participation. Aligned with this, there has been a recent trend towards competence-based teaching and learning with very significant changes in science school curricula. These changes involve more engaging cross-curriculum approaches emphasizing the development of different kinds of literacy, science knowledge and positive attitudes towards science as well as an increased use of "real-life" applications, providing appealing learning contexts, meaningful and related with students' social reality [2], [6].

Students need to understand basic science concepts, to use science process skills, to create meaningful connections with science, technology, society and environment, to develop values and attitudes towards science and to know the nature of science. Moreover, they need to improve some skills related to inquiry, critical thinking, problem solving and decision making. The increasing demand in these skills has been especially apparent at elementary grades [7].

In order to achieve high levels of literacy, international recommendations [2] point out the need for teachers to develop a critical teaching strategy, organize stimulating education environments, both in formal as well as non-formal settings, and guide to students towards self-regulated and challenging learning.

Teachers' strategies are therefore central in assuring the development and implementation of a new science education that activate and maintain the interest of students in science classes. Although interest is an essential dimension to make students engaged with learning and willing to learn science, teachers still have to use appropriate teaching strategies in order to promote learning in accordance with present aims of science education [8].

Inquiry-based science education has been highlighted as having the potential to increase students' engagement in science at all levels and to provide opportunities for competence development [2] promoting literacy integration. The inquiry approach in science teaching has been defined as 
the "intentional process of diagnosing problems, criticizing experiments, distinguishing alternatives, planning investigations, researching conjectures, searching for information, constructing models, debating with peers, and forming coherent arguments" [9]. Through this deeper engagement process students are presented with more opportunities to foster initiative-taking, creativity and innovation, being able to develop in schools different literacies in an integrated way.

The project intends to promote an effective science teaching and learning, through the development of multidisciplinary inquiry-based activities that involve an integrated approach of different literacy's, focused on marine ecology, to be applied in different learning contexts. These innovative activities are expected to be implemented not only in classrooms but also in non-formal education institutions, such as science centers, and research laboratories. With these activities we pretend to promote critical thinking and students' motivation towards science.

It is also important that students see themselves as capable of learning science, understanding nature of science, being able to participate in scientific discussions, adopting a critical stance while respecting the contributions of others, and willing to ask questions and revise their own opinion. This type of innovative learning environments implies that teachers need a wide range of teaching strategies, the knowledge of how and when to use them, and the ability to associate methods. The question that arises is what teachers need to assist them in this demanding task?

\section{PRoblem}

How to support teachers to adopt inquiry based science practices at elementary education?

\section{PROCEDURES}

\section{A. Description of the Activities}

Within the project we created and implemented multidisciplinary activities that involved an integrated approach of different kinds of literacy, both in classroom and, in non-formal education institutions. The activities were aimed at increasing students' motivation toward science and were based on the general theme 'Between tide marks', which provided 'real-life' situations as an appealing learning context.

The novelty of this project is to promote the integration of different kinds of literacy through the development of "learning itineraries". Within these itineraries, we offered a range of inquiry-based activities that are complementary and can be implemented at school, research laboratories, science museums, and field work, and that as a whole have the potential to address a real problem. The teacher was free to choose the itinerary to develop with a particular class and could follow different paths for exploration of the same theme. The developed activities were already implemented in several schools.

For each activity, teachers had access to: general information, with a brief description of the activity, objectives and resources; students' documents with description of the different tasks to be performed; teachers' documents including a brief scientific background and main scientific aspects explored, some implementation advices comprising possible competencies involved and its assessment, suggestion of experimental protocols when needed and additional resources such as internet sites and book references.

In this work we present two activities of the project, one related to fish adaptations and the other related to the effect of oil spills on organisms and their environment.

The main objective of the activity "fish adaptations" was to explore fish biodiversity and understand the relation between morphology and function. As a contextualization task, students were challenged to draw a fish. The majority of the fish drawn had all the same format and many had no fins. Then a question aroused: are all fish like this? To introduce students to fish biodiversity the teacher took them to visit a fish market where they could observe diverse fish, talk with vendors and discuss the reasons for the differences and similarities encountered. These observations were taken to classroom, where they discussed and systematized their learning, creating an identification card (IC) for each fish species. Moreover, they made a drawing by observation of a specimen brought, taking care to record its real characteristics and discussing the importance of doing that. Finally, they dissected the specimen and observed their internal organs and conducted an experimental activity to simulate the function of the fish gas bladder.

The activity related to oil spills emerged from the analysis of news about real petrol vessels accidents. After this engagement introduction students were invited to formulate questions about the impact of oil spills on the water, shore sediments and on organisms, namely birds. Students should be able to raise questions about the behavior of oil in the water, in sediments with different grain size (sand, silt, gravel), and on birds feathers. In this last case students should also reflect about the consequences for the birds and what could be done to mitigate the problem (for instance, how to clean feathers from oil). In order to answer to the questions raised, students had to plan experiments. The experimental procedures included the identification of variables and control, the implementation of the experiment, results and conclusions.

\section{B. Participants}

TABLE I: ACTIVITIES DONE PER SCHOOL, GRADE AND CLASS

\begin{tabular}{llll}
\hline \hline \multirow{2}{*}{ School } & Grade & Class & Activity \\
\hline Public school (A) & $3^{\text {rd }}$ & A & Fish adaptations \\
Private school (B) & $3^{\text {rd }}$ & B & Fish adaptations \\
& $3^{\text {rd }}$ & B & Oil in the water \\
& $3^{\text {rd }}$ & C & Fish adaptations \\
& $3^{\text {rd }}$ & C & Oil in the sand \\
& $4^{\text {th }}$ & D & Oil in the feathers \\
Private school (C) & $3^{\text {rd }}$ & E & Oil in the feathers \\
& $3^{\text {rd }}$ & F & Oil in the feathers \\
\hline \hline
\end{tabular}

The activities analyzed in the present study were done in three elementary schools (two private and one public school), and involved six teachers of the 3rd or 4th grade and a total of 
140 students. In the Table I we present the number of activities done per school, grade and class.

\section{Methodology}

To evaluate the activities implementation by the teachers and its impacts on students a qualitative research was done, following a case study methodology (multiple-case study) [10]. Data was collected using four instruments: interviews, questionnaires, observation, and document analysis. These instruments were applied in all schools and grades.

Two different questionnaires were used in this study. A closed questionnaire was applied to students in order to assess their opinion about the activities and the tasks they found more difficult. An open questionnaire was applied to teachers to understand how they implemented the activity, the major difficulties felt, and the students' engagement. Both questionnaires were applied at the end of each activity.

In addition, teachers and students were also interviewed at the end of the activity, in order to get a deeper understanding about the crucial aspects they considered as responsible for their engagement with the activities. Moreover, the activities were observed by one of the researchers to gather direct data about the implementation process, whenever the teachers consented. Finally, all documents produced by the students during the activities were subjected to a content analysis.

\section{RESULTS AND DISCUSSION}

\section{A. Fish Adaptations Activity}

Three teachers chose this activity. The teachers were actively involved in the activities, preparing documents for students, conducting the activities, gathering and organizing the documents produced by the students, applying the students' questionnaire, and answering the professors' questionnaire. However, the implementation process followed by them was considerably different.

Indeed, one of the teachers allocated a larger amount of time to the activity: one previous session to prepare and introduce the activity, a visit to a fish market, four sessions dedicated to research and elaboration of the fish identification card (IC) and one session to observe the fish internal organs and to perform the experimental activity to simulate the function of the fish gas bladder.

The other two teachers used one previous session to contextualize the activity, after they asked the children to go to fish markets with their parents and to research fish characteristics at home, and made one session in the classroom to the elaboration of the fish IC. These two teachers dedicated less time to this activity but they conducted the activity of oil spills as well (Table I).

The teachers' evaluation indicated that their major constraint in implementing the activities was time. The results from observation and of the students' documents revealed that the relation between form and function was not achieved in the classes that devoted less time to the activity, nor the observation competences required in specimens drawing.

One other aspect was that the IC of the students that had more time for discussion in the classroom had less information but more adequate to respond to the initial questions, while the students from the other classes produced IC with a large amount of information. Nonetheless, these students had the opportunity to do research at home and to integrate digital literacy in the activity. Parents' collaboration was also a positive aspect and resource for both students and teachers.

\section{B. Oil Spill Activity}

This activity was chosen by five teachers. However, instead of joining the different areas of conceptual knowledge (physics/chemistry, geology and biology) and to perform the three experiments to examine the behavior of the oil in water, in the sediments and in the organisms in sequence, the teachers chose only one of the three subjects. Therefore, each class did only one single experiment of this theme (Table I). At the end of the activity, the results obtained by each class were presented to the school community in a final exhibition.

Considering the work path followed by each teacher, three of them did not ask students to plan the experiment, and gave, instead, the experimental protocol already planned. The other two followed the initial proposal, asking students to plan the experiment and indicate the variables and control. The analysis of the documents produced by the students showed that in the case of the activity related with the behavior of oil in the sediments, students showed several problems in the interpretation of the results. In contrast, students that worked with a closed protocol and more orientation had fewer difficulties in understanding the experimental results.

\section{Teachers and Students Evaluation}

According to the questionnaire analysis all students enjoyed performing the activities. The majority of them pointed out the team work $(56 \%)$, the mobilization of scientific knowledge (37\%) and the need to make decisions on how to organizing the work $(29 \%)$ as positive aspects. The difficulties felt by the students included the research in books and other sources (23\%), have to identify one problem (22\%), to make decisions $(21 \%)$ and to draw conclusions (19\%). (Table II).

TABLE II: STUDENTS PERSPECTIVE

\begin{tabular}{lcll}
\hline \hline Positive aspects & $\%$ & Major difficulties & $\%$ \\
\hline $\begin{array}{l}\text { Working in team } \\
\text { Mobilizing scientific }\end{array}$ & 56 & Researching information & 23 \\
$\begin{array}{l}\text { knowledge } \\
\text { Making decisions on how } \\
\text { to organize the work }\end{array}$ & 29 & Making decisions & 22 \\
& & Drawing conclusions & 19 \\
\hline \hline
\end{tabular}

Teachers also made a positive evaluation of the activities performed, stressing as positive aspects the actuality of the themes and the importance of exploring new concepts with the students. In the case of the "fish adaptation" activity, they highlighted the observation of the internal organs of the fish and the experiment done to simulate the gas bladder.

Students seemed to understand the function of the gas bladder:

"We also understood that the reason why a fish floats is the gas bladder, which is an organ full of air inside the fish" 
(student interview).

For the teacher, this was actually the main novelty:

"For this group the great novelty was the dissection of the fish" (teacher interview).

In addition, in all classes involved, students also emphasized the acquisition of scientific knowledge related with fish ecology:

"I learnt that the body format of the fish is related with its habitat" (student interview);

"With this activity we learnt what each fish eat, where it lives" (student interview).

In the case of the "oil spill" activity, both teachers and students stressed the importance of performing experiments. In this case, the main difficulty referred by students was related with the experimental planning:

"The difficulties we had were to know what to mixture to do the right experiment (student interview)" or "I had difficulties in explaining my ideas to plan the experiment" (student interview).

Indeed, one of the teachers referred that planning "was their main difficulty, but also the aspect in which they learned more" (teacher interview).

However, teachers also mentioned some negative aspects that should deserve more attention. The main difficulty stressed by all of them was time constraints. Indeed, many of the options taken by the teachers, namely the option to not perform certain tasks suggested (the visit to the market or the dissection of the fish), or to solicit students to work some aspects at home (research about species characteristics), or even to give students a protocol to follow instead of asking them to plan the experiment, were justified because these options were excessively time consuming.

Another difficulty referred by some of the teachers, namely those of the 3rd grade, relates with the lack of adjustment of the activities to students' age. Finally, all of them stressed out the need to have more specific guidelines and supporting material, like more information about the type of materials needed to do the experiments, links to internet resources where students could search information, and teacher support documents with scientific information to discuss the activity with students.

\section{FinAl REMARKS: CONTRIBUtions TO THE TEACHING AND LEARNING OF SCIENCE}

Science education literature advocates the need to implement innovative classroom activities, such as research activities and real problem solving, which enables students to mobilize and integrate different competences in order to construct explanations and/or coherent arguments, related with everyday life socio-scientific issues [2]. These types of activities must have students as their main actors, allowing that the inquiry gives rise to research, to data selection and organization, to confront ideas, to argue and to experimentation, when necessary.

The challenge for teachers is to develop teaching and learning approaches that showcases science education in such a manner that will appeal as being significant and worthwhile, resulting in greater engagement and scientific understanding by those involved [11]. Teaching and learning materials are required to meet these criteria and assist teachers in their endeavors to make science teaching more relevant.

However, teachers have also the key role to promote and implement these activities in the classroom. The creation of new curriculum materials can facilitate the adoption of new practices by teachers. Nevertheless, it is not sufficient to just provide teachers with new materials ready for use, it is essential to make it in a broader context of promoting professional development [12].

In this study, the implementation process of each proposed activity was different between teachers and consequently the students' achievements were also different in each class. Time constraints to apply the activities were considered a difficulty referred by several teachers. This led them to choose a single activity instead of one learning itinerary or to ask students to do research at home instead of doing it in the classroom.

To overcome this situation it would be necessary a major investment in professional development for teachers within the project tasks (presence or online), and in meeting events where they could see and discuss the educational resources, in order to get involved and to choose the activities and learning itineraries to follow. A checklist could also be advised before the implementation of the activities with several steps: planning the itinerary or activity; reading the scientific background information and see how themes are related to the curriculum; organizing activities and students worksheets; making decisions on how the class will explore the activity.

Teacher's ownership of the activities [13], the understanding of its relevance and curricular integration, knowledge of the strategies developed are perhaps the keystone of this entire process. Particularly, adequate curricular integration of the activities can help teachers' time limitations. Nevertheless, this change process requires support, teachers training, involving them in reflecting on their own experiences and ideas, in developing new practices, new materials and new teaching strategies.

The research in science education that guides the critical curricular perspectives indicates that teachers are at the heart of the change [2], [14]. In order to promote a change of perspective in science education, teachers should develop teaching strategies of critical thinking, organize learning challenging environments, give careful support to students for their self-regulation and learning, based on problem solving and decision making [15]-[18]. However, this type of teaching demands has profound implications for the competencies which teachers themselves need to acquire to effectively teach 21 st century skills to their students.

The kind of education needed today requires teachers to be high-level knowledge workers who constantly advance their own professional knowledge as well as that of their profession [19]. Indeed, the OECD's comparative review of innovative learning environments concludes that teachers need:

- To be well-versed in the subjects they teach in order to be 
adept at using different methods and changing their approaches to optimize learning;

- A rich repertoire of teaching strategies, the ability to combine approaches, and the knowledge of how and when to use certain strategies;

- To have a deep understanding of how learning happens, in general, and of individual students' motivations, emotions and lives, in particular;

- To be able to work in highly collaborative ways, working with other teachers and professionals, networks of professional communities and different partnership arrangements, which may include mentoring teachers;

- To acquire strong skills in technology and its use as an effective teaching tool, to both optimize the use of digital resources in their teaching and use information-management systems to track student learning;

- To develop the capacity to help design, lead, manage and plan learning environments in collaboration with others;

- To reflect on their practices in order to learn from their experience.

One of the key challenges for the teaching profession is to strengthen the "technical core" of its professional practices [19]. As a result, other questions can be posed: what does it take to improve the use and dissemination of proved and promising teaching practices? How do we generate and share cumulative knowledge in education?

This requires the development of educational networks that support the creation, accumulation and diffusion of this professional experience, and simultaneously give teachers confidence and competence to be reflective practitioners and effective managers of information and knowledge.

\section{ACKNOWLEDGMENT}

The study was supported by the project 'Between tide marks: Integrating literacy's (iLit)' (PTDC/ CPE-CED/ 117923/ 2010).

\section{REFERENCES}

[1] National Research Council [NRC], Taking Science to School: Learning and Teaching Science in Grades K-8, Washington: National Academic Press, 2006.

[2] J. Osborne and J. Dillon, Science Education in Europe: Critical Reflections, King's College London: The Nuffield Foundation, 2008.

[3] European Parliament and Council, "Recommendation of the European Parliament and of the Council on key competences for lifelong learning," Official Journal of the European Union, vol. 394, pp. 10-18, 2006.

[4] American Management Association, Critical Skills Survey, Washington: Author, 2010.

[5] P. Griffin, B. McGaw, and E. Care, Assessing and teaching for 21st century skills, Dordrecht, NY: Springer, 2012

[6] R. W. Bybee, "Teaching science as inquiry," in Inquiring into inquiry learning and teaching in science, J. Mintrell and E. H. van Zee, Eds., Washington DC: American Association of the Advancement of Science, 2000 , pp. 20-46.

[7] J. Holbrook and M. Rannikmae, "Nature of science education for enhancing scientific literacy," International Journal of Science Education, 2007, vol. 29, no. 11, pp. 1347-1362.

[8] D. Palmer, "Student interest generated during an inquiry skills lesson," Journal of Research in Science Teaching, vol. 46, no. 2, pp. 147-165, 2009.
[9] M. C. Linn, E. A. Davis, and P. Bell, Internet Environments for Science Education, Mahwah, NJ: Lawrence Erlbaum Associates, 2004.

[10] R. K. Yin, Case study research: Design and methods, Thousand Oaks, CA: Sage, 2003.

[11] A. Schleicher, Preparing Teachers and Developing School Leaders for the 21st Century: Lessons from around the World, OECD, 2012.

[12] I. Milne, "A sense of wonder, arising from aesthetic experiences, should be the starting point for inquiry in primary science," Science Education International, vol. 21, no. 2, pp. 102-115, 2010.

[13] D. J. Clandinin and F. M. Connelly, "Teacher as curriculum maker," in Handbook of research on curriculum. A project of the American Educational Research Association, P. W. Jackson, Ed., New York MacMillan Publishing Company, 1992, pp. 363-401.

[14] M. Fullan, The Six Secrets of Change, San Francisco: Jossey-Bass, 2008.

[15] O. Autio, T. Kaivola, and J. Lavonen, "Context-based approach in teaching science and technology," in How Finns Learn mathematics and science, E. Pehkonen, M. Ahtee and J. Lavonen, Eds., Rotterdam: Sense Publishers, 2007.

[16] European Union, Europe needs more scientists, Report by the High Level Group on Increasing Human Resources for Science and Technology in Europe, Brussels: author, 2004.

[17] European Commission, Science Education Now: A Renewed Pedagogy for the Future of Europe, Brussels: Author, 2007.

[18] UNESCO-ICSU, Declaração sobre a Ciência e o uso do saber científico, Paris: UNESCO, 1999.

[19] A. Schleicher, Preparing Teachers and Developing School Leaders for the $21^{\text {st }}$ Century: Lessons from around the World, OECD, 2012.

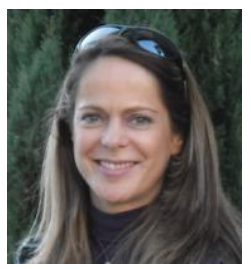

Diana Boaventura was born in Lisbon in 1970. She has a degree in biology, Lisbon University, Portugal, 1993; a MSc in ecology, management and modelling of marine resources, Lisbon University, Portugal, 1996; a PhD in marine sciences - marine ecology, University of the Algarve, Portugal, 2001; and a post-graduation in education - specialization in science didactics, Lisbon University, Portugal, 2006 The author's major field of study is marine sciences and science didactics.

She works at Escola Superior de Educação João de Deus, Lisbon, Portugal, since 2002. Previous working experience includes lecturing at Instituto Piaget, she was also an invited assistant at the University of the Algarve and at the Faculty of Sciences in the University of Lisbon. Current research interests include: Science Education- Integrating literacies and promotion of inquiry activities in elementary school; and Experimental Ecology- structure and functioning of rocky shore communities and the effects of global climate change on ecosystem functioning.

Dr. Boaventura has 74 scientific publications, of which 24 are articles in international journals with referees, and she has presented over 40 communications in conferences. She is referee of several scientific journals and has experience in Research Projects and $\mathrm{MSc}$ and $\mathrm{PhD}$ thesis supervision.

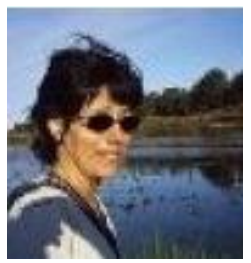

Cláudia Faria was born in Lisbon, in 1967. She has a degree in biology, Lisbon University, 1992; a Msc in ethology, ISPA, 1996; a PhD in ecology \& biosystematics, Lisbon University, 2001; a $\mathrm{PhD}$ in science education, Lisbon University of Lisbon, 2013; and a post-graduation in education - science education, Lisbon University, 2006 and another in data analysis in social sciences, ISCTE, 2009.

She currently works as a researcher in science education at the Institute of Education of the University of Lisbon. She has been developing research focused on designing innovative strategies for teaching and learning science, which explore the complementary role of formal learning contexts and informal ones (such as science museums and research laboratories).

Dr. Faria has been involved in numerous research projects in both areas, biological sciences and science education: eight national projects, including one as a PI, and two international projects. The results of her research activity have been published in peer-reviewed journals, book chapters, and presented in national and international conferences. In total, she has published 43 scientific papers. These have been widely cited. She has also written three book chapters and one book and presented 38 conference papers, three of which as invited speaker. 